\title{
Do we need disasters to adopt more environmental policies?
}

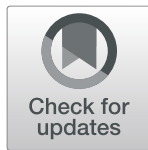

Sherief Emam", Thomas Grebel ${ }^{1}$ and Ana-Despina Tudor ${ }^{2}$

\begin{abstract}
Background: In this paper, we try to shed light on the question whether natural disasters, such as nuclear accidents, have an impact on policy makers' activity in passing new green energy policies. Disruptive moments like exogenous shocks reinforce society's disapproval against polluting technologies and should open a window of opportunities to eventually initiate a change toward green energy.

Methods: Based on the data of 34 OECD countries, we disentangle the effect of disruptive exogenous shocks on countries' policy activity. Starting with OLS regressions, we run several robustness checks by using a pre-sample mean approach, an ARDL technique called dynamic heterogeneous panel models (DHPM), which allows for the distinction between long- and short-run effects.

Results: The results corroborate the hypothesis that unexpected, disruptive events have a positive impact on the actual number of renewable energy policies. The fade-out time for shocks is about 7 years, leaving a positive longterm effect.

Conclusion: Exogenous events such as nuclear disasters act as "focusing event" and seem to offer policy makers a window of opportunities to initiate conducive policy measures toward a cleaner economy. Furthermore, a country's capacity in green technologies is key to a pervasive diffusion of green technologies.
\end{abstract}

Keywords: External shocks, Nuclear accidents, Policy change, Renewable energy policies

\section{Introduction}

The dangers of climate change have long been known. Global warming along with a rising sea level increased intensity and frequency of extreme weather events [1-3] threaten our livelihood. Apart from the negative effect on economic development, beyond and above all, it is our health that is at stake. Rising temperatures will make life impossible in many regions that are already struggling with heat. The cultivation of staple food becomes more costly and difficult [4]. In spite of all the damaging consequences, global emissions are still on the rise [5].

The reasons for this political sclerosis are threefold. Firstly, it is difficult for the public to understand climate

\footnotetext{
* Correspondence: sherief.emam@tu-ilmenau.de

${ }^{1} T$ U IImenau, Ehrenbergstr. 29, 98684 IImenau, Germany

Full list of author information is available at the end of the article
}

change. Already, the time dimension causes problems in doing so. A single hot summer day does not prove climate change, a persistent increase in average temperature however does, although $2{ }^{\circ} \mathrm{C}$ might sound little [6]. Secondly, climate change is delocalized, meaning that the polluters are not necessarily those directly affected. Atoll countries, for example, despite little domestic emissions suffer from a declining habitat due to climate change [3], whereas the effects on industrialized countries emitting a multiple of greenhouse gases are less immediate and therefore less obvious to the public. This makes it difficult for the broad public to discern the injured from the injuring party. So it thirdly is little surprising that the awareness of having to act against climate change is little pronounced in the public eye [710]. The public reacts if it can "see" or "feel" the obvious consequences of a pressing problem. It seems that only

(c) The Author(s). 2020 Open Access This article is licensed under a Creative Commons Attribution 4.0 International License, which permits use, sharing, adaptation, distribution and reproduction in any medium or format, as long as you give appropriate credit to the original author(s) and the source, provide a link to the Creative Commons licence, and indicate if changes were made. The images or other third party material in this article are included in the article's Creative Commons licence, unless indicated otherwise in a credit line to the material. If material is not included in the article's Creative Commons licence and your intended use is not permitted by statutory regulation or exceeds the permitted use, you will need to obtain permission directly from the copyright holder. To view a copy of this licence, visit http://creativecommons.org/licenses/by/4.0/ The Creative Commons Public Domain Dedication waiver (http://creativecommons.org/publicdomain/zero/1.0/) applies to the data made available in this article, unless otherwise stated in a credit line to the data. 
after some natural disaster (i.e., hurricanes or heatwaves) the public becomes aware of the possible dangerous consequences of climate change. As it has been observed in previous studies, people search the Internet for keywords such as "climate change" or "global warming" [11].

This phenomenon is even more obvious in the case of nuclear energy production. The danger of nuclear technology has been known ever since its discovery. Exposure to nuclear radiations can lead to environmental distraction [12], food insecurities [13], and health complications $[14,15]$. On the other hand, energy produced by nuclear technology is stable and relatively low in price. Therefore, public awareness and beliefs about possible consequences are heterogeneous across countries and fluctuating over time [16, 17]. For instance, Bisconti [18] analyzed long-term public opinion data and concluded that the larger portion of the US public takes a neutral position concerning nuclear energy. For example, $64 \%$ of the population neither strongly favor nor oppose nuclear energy. However, changes in public opinion can be observed as an immediate consequence of sudden nuclear accidents, where generic support for nuclear energy decreases. Such a decrease in support was reported in a cross-country public opinion survey (WIN-Gallup). In April 2011, after the accident of Fukushima, an average of $8 \%$ loss in nuclear energy support was measured in 47 countries [18]. Taking this into consideration, it is plausible that accidents would raise public concern and, in turn, result in changes on the political level as a search for alternative solutions.

Hence, an unexpected crisis, such as nuclear accidents, can help accelerate the political process. Policies previously excluded from the political agenda suddenly are brought back and appear enforceable. According to the policy literature [19], these events become so-called focusing events. They make citizens as well as politicians alert to the risks of nuclear power production or climate change. In the aftermath of the nuclear accident in Fukushima, Germany took drastic decisions concerning the phase-out of nuclear energy. As a response to decreasing public support for nuclear power, the government decided to shut down seven reactors temporarily and to accelerate the phase-out of nuclear energy production [20]. Similar reactions took place in other countries, where governments rethought their energy production strategy and decided to withdraw from nuclear power production. For instance, Switzerland voted for a phase-out by 2034 [20]. In Japan, after the Fukushima accidents, the government shifted its energy consumption to fossil fuel resources [21].

The main interest in policy research is to investigate the challenges of their implementation or ex-post-the evaluation of policy effectiveness [22-24]. Scholars investigate the challenges when implementing policy measures [25]; however, the vast majority of studies address policy effectiveness questions, to wit, whether policies positively affect green innovation [26-29], the potential of policies to reduce carbon dioxide emissions [30], or whether they contribute to economic growth $[31,32]$.

To our knowledge, there is little work on the possible determinants triggering respective green policies. We raise the question if external shocks can work as incentives for decision-makers to pass new renewable energy policies. In other words, we ask whether these accidents function as a catalyst, i.e., as a focusing event $[31,33]$ for policymaking. The strand of literature, to which we intend to contribute, is the so-called Advocacy Coalition Framework (ACF) as put forward by Jenkins-Smith and Sabatier [34]. This concept offers a general frame explaining the basic mechanisms of shifts in policymaking. ${ }^{1}$ As, for instance, Nohrstedt [33] points out, the ACF links the momentum of external shocks (i.e., nuclear accidents) to the consequential policy initiatives arising from it. Complementary to the abundance of micro studies in the literature, we add a quantitative crosscountry comparison quantifying the results of a crisis to policy change on the theoretical grounds of the ACF.

The data we use is gathered from various data sources. From the International Energy Agency, we collected about 60 different supply and demand side policies in renewable energy of 34 OECD countries. ${ }^{2}$ For identifying nuclear accidents as possible focusing events triggering new renewable energy policies, we perform several regression models such as ordinary least square regressions, followed by count data models; to distinguish between short-run and long-run effects, we perform dynamic heterogeneous panel model (DHPM) estimation. Thus, we retrieve a proxy for the fade-out time of shocks. The proxy will be implemented in further robustness checks. Additionally, several controls are included in the models, such as energy prices, power production capacities, and shares of renewable energy production.

The results suggest a significantly positive effect of nuclear disasters on the enactment of renewable energy policies. The shock, according to our calculations, fades out after about 7 years, indicating that the "window of opportunity" for policy makers lasts about 7 years. Finally, evidence for an increase in $R \& D$ as well as diffusion policies after both Fukushima and Ibaraki are found; however, no effect was found for either of the policies after Chernobyl.

\footnotetext{
${ }^{1}$ See also Schlager [35], Sotirov and Memmler [36], Sabatier [37, 38], Henry et al. [39], Kübler [40], and John [41].

${ }^{2}$ The data have also been used in studies by Nesta et al. [26], Johnstone et al. [42], Popp [28], and Fischer and Newell [30].
} 
We may conclude that severe external shocks, such as nuclear accidents, redirect policy makers' attention. Such shocks function as "focusing events" which finally have policy makers reconsider their policy agenda. They are catalytic moments that help (political) actors form coalitions to eventually bring about policy change and introduce supportive policies such as policies promoting renewable energy technologies.

Moreover, as longing for further external shocks cannot be a serious policy implication, it remains to pose the question whether there is a comparably effective policy momentum to create the same effect as external shocks. This question, however, cannot and is not to be answered with this research setting.

The rest of the paper is organized as in the following. In the "Background" section, we discuss the concept of the Advocacy Coalition Framework (ACF) and our adaptation of the ACF for empirical testing. The "Data" section delivers descriptive statistics, lays out our general empirical approach, and discusses the econometric specification of models. Results are presented in section 3 including robustness checks, endogeneity issues, and the differentiation between long- and short-run effects. A discussion and conclusion round off the paper in section 4 .

\section{Background}

\section{Crises, focusing events, and the advocacy coalition framework (ACF)}

Nuclear accidents mark moments of crisis, they manifest "...a combination of severe threats, high uncertainty, and the need for urgent decision making" ([43], p. 557). ${ }^{3}$ In policy change literature, crises are often considered as "focusing events." Birkland [49] distinguishes three categories: (1) normal events which can be expected to happen but are unpredictable such as earthquakes, hurricanes, or nuclear disasters; (2) new events which refer to unprecedented events as induced by technological change, or the usage of new products; and (3) common events under uncommon circumstances. This type of events refers to events which occur on a regular basis but cannot be predicted where and when it happens. School shootings would be one those examples [50].

\footnotetext{
${ }^{3}$ There are many terms in the literature which relate to the concept of "crisis." These concepts refer to different situations in academic discourse; however, they are clearly related [44]. They can be defined as a situation of large-scale public dissatisfaction, where communities perceive an urgent threat to core values of life or even fear stemming from an unusual degree of social unrest or economic problems or even threats to national security (Keeler [45], Flanagan [46], Rosenthal et al. [47]). Both crises and disasters deal with events that belong in the "unness" category: unexpected, undesirable and often unmanageable situations Hewitt [48].
}

With respect to policymaking, the bigger the accident, the more attention is paid to the underlying political issue. Nuclear disasters, although labeled normal event, are major events and unpredictable. Once an accident occurs, as Nohrstedt and Weible [51] point out, the emerging crisis becomes a focusing event, which has political actors focus on the issue and become aware of the potential consequences of such accident. This moment opens up an opportunity to come to a democratic consensus and make a change. Therefore, such events are frequently considered causal drivers for major or nonincremental policy changes.

The underlying mechanism, how such kind of events lead to policy change, can be described with the so-called Advocacy Coalition Framework (ACF) as suggested by Sabatier and Jenkins-Smith [52]. It is a general framework explaining the basic mechanism how shifts in policymaking occur, while linking the momentum of crisis to the consequential policy initiatives arising from it [33].

Figure 1 sketches the basic concept in a simplified version. According to Sabatier and Weible ([53], p. 191), (1) policymaking takes place among specialists (macro perspective) who are influenced by many factors of the political as well as the socio-economic system; (2) actors decide within lines of certain political and social context, even if once taken decisions may not necessarily be perfectly rational (micro perspective); ${ }^{4}$ and (3) actors need to form advocacy coalitions in order to have a say in the political process (meso perspective) ${ }^{5}$ As a consequence, subgroups emerge which share common expertise, interests, and beliefs. It is the coalitions that take influence on the decision-making process within a given political subsystem, which eventually results in the specific design of the institutional frame or the (re-)distribution of resource. ${ }^{6}$

\footnotetext{
${ }^{4}$ This micro concept is taken from social psychology and is in contrast to rational choice theory. The concept refrains from the orthodox economic approach of methodological individualism. Decision-making is not performed in isolation as if actors behave purely rationally. Conversely, the ACF follows the normative grounds of March and Olsen [54], who argue that decisions are made in accordance with the "logic of appropriateness" and the "logic of consequences"; decision makers follow rules and intend to maximize good consequences. Compare Sabatier and Weible ([53], p. 194). This also explains the inertia in the political system; it is not sufficient when individuals change their mind. It needs the majority of a group to come to new beliefs and convictions. Only if the majority shares new common attitudes, beliefs, or interests, a change in the coalition's strategy can occur.

${ }^{5}$ With regard to an endogenous concept of change, rule-based behavior, and meso economics, see also Dopfer and Potts [55], Dopfer [56], and Dopfer et al. [57], respectively.

${ }^{6}$ It shall be stressed that coalitions are not confined to political parties rather than any kind of participant in the political process such as interest group leaders, journalist, or researchers.
} 


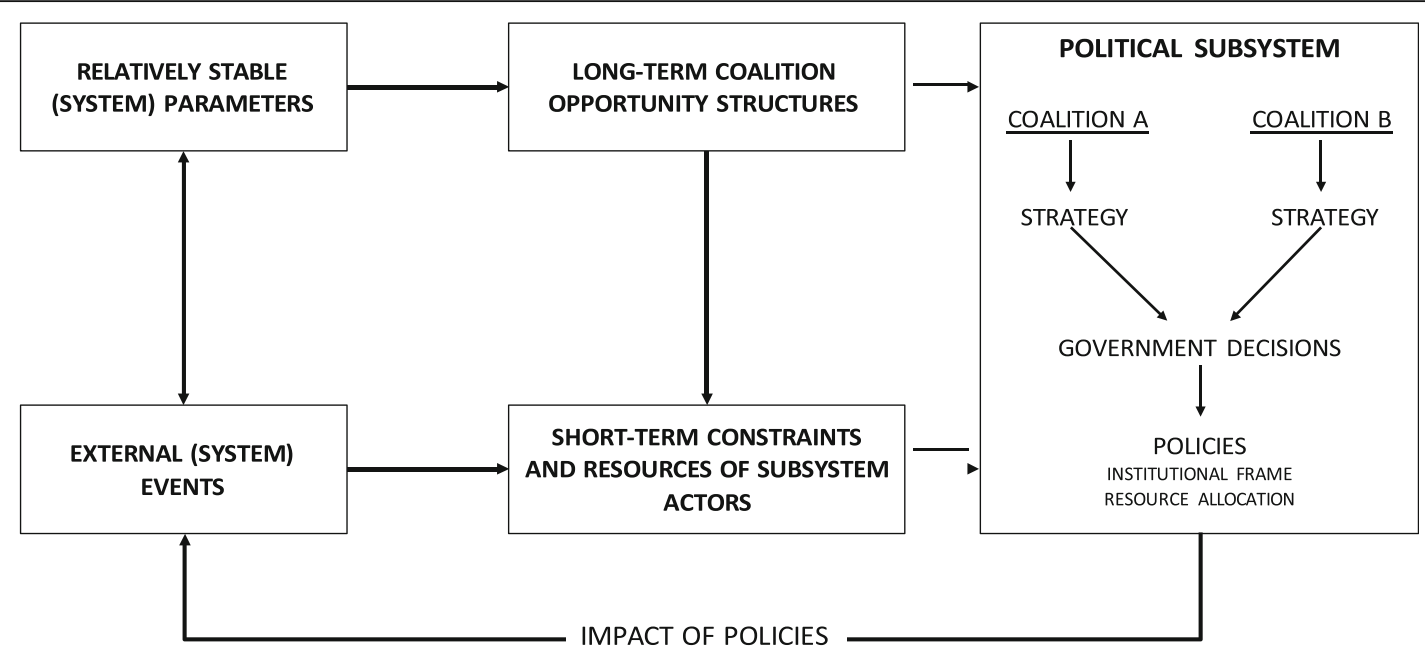

Source: Adapted from Sabatier and Weible [53].

Fig. 1 Advocacy Coalition Framework. Source: Adapted from Sabatier and Weible [53]

The emergence and the development of political subsystems are determined by the opportunity structure constituted by actors, subgroups, and the prevailing participation pattern. The more diverse beliefs or attitudes, the more difficult to form coalitions. Some coalitions may remain uninfluential because of their (short-term) resource constraints, or they may simply lack the funds to make themselves be heard in the political process.

Whether a policy change is actually initiated or not depends on various factors. The political proximity and the geographic proximity play a decisive role [45-47]. The closer political parties' proximity, the simpler a consensus to achieve. The more geographically concentrated the point of interest, the less difficult the opinionforming process. Also, the political system itself may represent an inhibiting factor, since the inert institutional setting of a political system, may create a "...policy equilibrium, that cannot be changed from within." ([51], p. 3). Hence, an external shock can help destruct the political equilibrium and initiate a policy change [51]. Whether the effect of a crisis is long-lasting or not depends on the severity of the crisis: the bigger the cause, the bigger the impact [45-47]. But it is also conceivable that small events have a large and enduring political consequence [58]. Further complexity is added by the fact that not all system parameters are stable over time. Some are rather stable, such as the constitutional structure, the social structure, or the socio-cultural values within society, and others may change substantially, such as the public opinion or the socio-economic conditions. The holistic approach of the Advocacy Coalition Framework (ACF) captures all these factors that take impact on the participating subsystems within the political decision-making process.

\section{A simplified ACF for empirical testing}

For the purpose of this paper, we will not elaborate any further on the ACF as such. Instead, we intend to use the concept to describe the country-specific context in which external shocks, i.e., nuclear disasters, may have an impact on the political process. To date, most empirical studies focus on case studies. ${ }^{7}$ Instead, we want to perform a quantitative study evaluating the impact of external shocks on political activity in 34 OECD countries. For this reason, the ACF must be simplified even further. The perspective of case studies using the ACF model is quite detailed and differentiates many micro-level parameters which cannot be identified when it comes to country comparisons. To our knowledge, there is no available data set, which would contain all required variables for a detailed description of the underlying mechanisms. ${ }^{8}$ As we deal with annual data, we concentrate on system elements trackable on a yearly basis.

On these grounds, we reduce the ACF to an even simpler representation in Fig. 2. Three building blocks remain in our version of the ACF. The (1) Relatively Stable Parameters, as in the original version, reflect the substratum of the Long-term Coalition Opportunity Structure, with which we will proxy the persistence of the political system of a country; (2) the representation of the country-specific political subsystem, labeled Current Political Balance of Power, which is held responsible for decisions made on policy measures; and (3) the resource constraints referring

\footnotetext{
${ }^{7}$ Compare appendix in Sabatier and Weible [53] for further information.

${ }^{8}$ Not only would we need to identify possible proxies for each element, including their interdependencies, we would also need to have data of higher frequency, since many changes in the political process may occur within days, weeks, or months.
} 


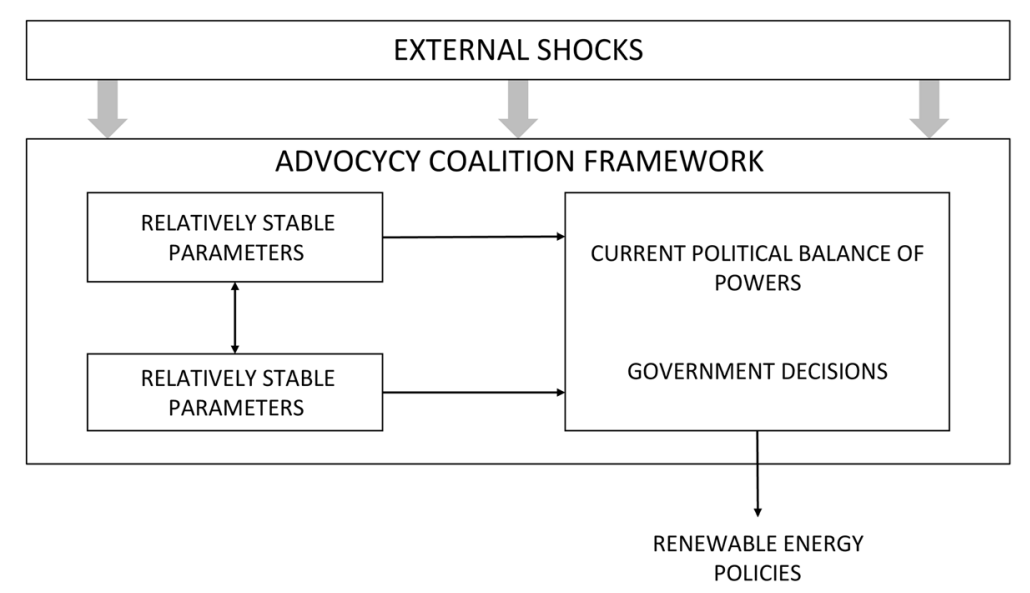

Fig. 2 Simplified Advocacy Coalition Framework

to a country's temporary socio-economic context in which policymaking occurs. ${ }^{9}$

Based on the country-specific ACF, we can now look at the effects external shocks have on political activity. Nuclear disasters are major events with great impact on the policy due to their gravity and breadth, as they affect political, environmental, and societal levels. The nuclear events in the last decades, which represent severe external shocks, are the accidents in Chernobyl, Ibraraki, and Fukushima. Their severity can be measured by the International Nuclear Event Scale (INES) introduced by the International Atomic Energy Agency (IAEA) in 1990. The classification ranges from 0 to 7 , where 0 means that a nuclear incident has no significant effects on safety and 7 reflects an accident with a "major release of radioactive material with widespread health and environmental effects requiring implementation of planned and extended countermeasures." ([59], p. 3). The accident in Chernobyl in 1986 was rated 7, the accident in the year 1999 in Ibaraki rated 4, and the Fukushima accident rated $7 .{ }^{10}$ In other words, these three accidents can be considered as focusing events, with the potential to trigger a policy change. It is expected that they open up an opportunity to bring renewable energy back on the policy agenda and that they not only gain increased attention but turn into actual measures. This is what Baumgartner and Jones [60] point out: after disasters, the agenda experiences a rapid growth, which in the case of nuclear accidents should accordingly translate into an increase in renewable energy policies. Nohrstedt $[61,33]$

\footnotetext{
${ }^{9}$ This is quite different from the understanding of short-term resource constraints in the original ACF. In the latter, the constraints relate to the actors of political subgroups. Since this micro-level information is not available across all countries, we interpret resource constraints as the constraints given by a country's economic context.

${ }^{10}$ According to the INES scale, an incident rated 4 or above is considered a severe accident [59].
}

investigating the impact of nuclear accidents on nuclear energy policies provide corresponding evidence for the Swedish case. This leads us to the hypothesis that, along the lines of our simplified ACF, the focusing event of a nuclear accident should eventually lead the political system to increase green energy initiatives.

Though a crisis may be a "little push" to catch public attention [34, 62], an event on its own does not make policy change. Event attributes, as Birkland [49] and Birkland and Warnement [50] argue, are important in policy change; the crucial element, however, is the "political climate." An event-driven policy change takes place, when problems are matched with feasible solutions together with political concordance [62]. He refers to this moment as a "window of opportunity." Likewise, Zahariadis [63] argues that policy windows are a result of problems, i.e., crises. Also, windows of opportunity do not open eternally. It depends on the severity of a crisis and the size of a mandate [45]. Therefore, we will also test the hypothesis, whether a timely limit in the "windows of opportunity" can be detected.

Last but not least, the historicity of events needs to be considered. A policy change toward green technologies requires the existence of feasible technologies. Without available innovations/inventions, their diffusion is impossible. Nowadays, renewable energy technologies are far more advanced than at the time of the nuclear accident in Chernobyl. This implies that also the kind of policies should have changed over time. While policies supporting research and development should have been prevalent in the 1980s, diffusion-oriented policies should have gradually become more important over the years. This hypothesis we also test in this paper.

\section{Method}

In this section, we describe our econometric protocol and the data with which we proxy the building blocks of 


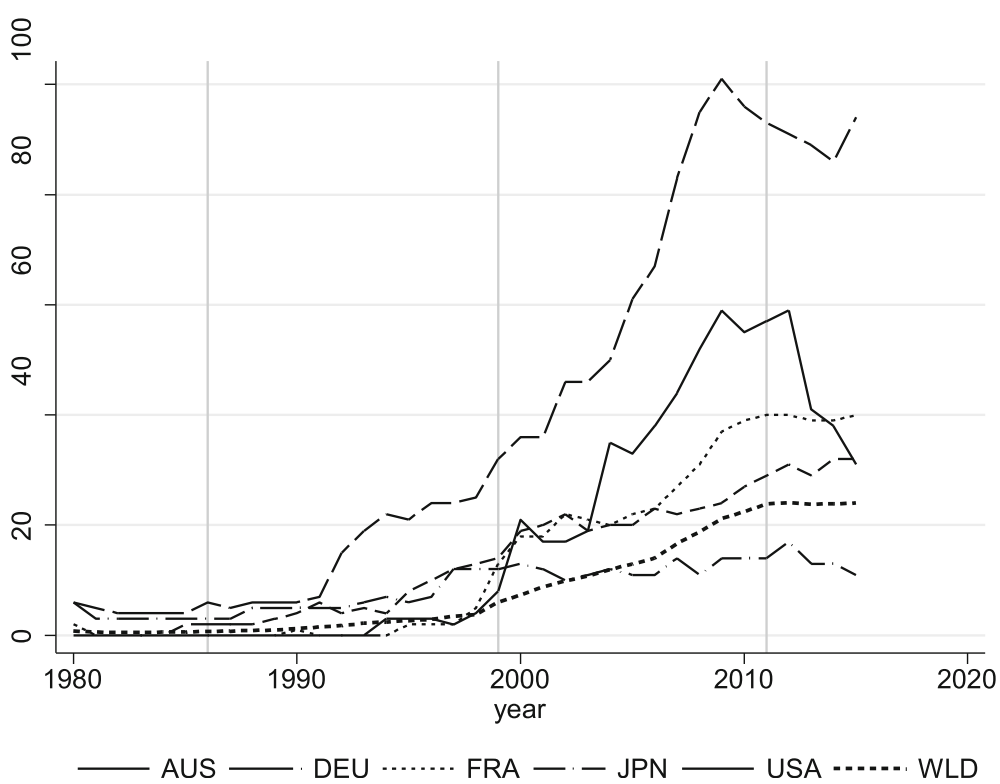

Fig. 3 Accumulated renewable energy policies index. Vertical lines indicate the nuclear accidents. Source: own calculations from IEA data

our simplified ACF above. We test the effect of external shocks, i.e., nuclear disasters, on political activity in countries. For that, we perform panel data regressions such as two-way fixed effects, pre-sample mean, and count data regressions. Moreover, a heterogeneous dynamic panel regression shall help identify the time of shocks to fade out. This information will be used as a proxy for the timely limit of the windows of opportunity with which we will recalculate previous panel regressions. In addition, the distinction between types of policies will shed light on the change in policymaking over time, as diffusion-oriented policies should gain importance while the role of R\&D-oriented policies should decline.

\section{Data}

The data we collected is an unbalanced panel data set of 34 OECD countries from 1980 to 2015. Thereof, the information about renewable energy policies (REP) stems from the International Energy Agency (IEA). The data on the Relatively Stable Parameters we took from Scartascini et al. [64]. Economic indicators to proxy Resource Constraints were retrieved from the OECD database. Energy prices and further information about countries' energy production system also come from the IEA.

As dependent variable throughout all regressions, we use the number of renewable energy policies in force during a given year. As in Johnstone et al. [42], Nesta et al. [26], and Dasgupta et al. [65], we build a policy index by counting the number of effective renewable energy policies by country, see Fig. 3. The time span of effectiveness can be derived from the reported information about the year of adoption and expiration of the renewable energy policy. The aggregated index covers all available types of renewable energy policies. ${ }^{11}$ The drawback of this variable is that it does not compare on a cardinal basis nor does it provide any information about the actual scope of a policy. In addition, the aggregation across different types of renewable energy policies in a single index incurs a loss of information in terms of policy-specific individual effects [42]. Nevertheless, it allows us to track the activity level of policy makers.

Whether natural disasters matter certainly depends on their magnitude. The extent of nuclear disasters is classified according to the International Nuclear Event Scale (INES) introduced by the International Atomic Energy Agency (IAEA) in 1990. ${ }^{12}$ The classification ranges from 0 to 7 , where 0 means that a nuclear incident has no significant effects on safety and 7 reflects an accident with a "[m]ajor release of radioactive material with widespread health and environmental effects requiring implementation of planned and extended countermeasures." ([66], p. 3). Concerning the three accidents we chose for our analysis, they all are considered major accidents with an INES level of at least 4. The accident in Chernobyl in 1986 was rated 7, the accident in the year 1999 in Ibaraki Tokaimura rated 4 , and the Fukushima accident rated 7 . In other words, these three accidents can be

\footnotetext{
${ }^{11}$ The IEA also reports different kinds of policies such as policies considered economic instruments, regulatory instruments, policy support, and information and education.

${ }^{12}$ See International Atomic Energy Agency [66].
} 
considered as focusing events, which eventually may impact the political decision-making process.

\section{ACF model parameters}

To proxy the Relatively Stable Parameters of the ACF, we select the variable Established Democracies from the Database of Political Institutions 2017 [64]. It counts the number of years when a country has been democratic. In the case of countries that have been democratic even before 1980 , this variable represents a monotonously increasing line with slope one. It is expected that the more democratic a society, the stronger its tendency to pass more renewable energy policies.

A further indicator of this database that we use is the variable Autonomous Region. This variable indicates whether a region can make autonomous decisions independently from some other institutional authority. If a region is independent, it can pass its own legislation without the need to be granted a permission from some other authorities. This in turn should enable regions to be more active and pass more green policies in the aftermath to nuclear disasters.

As a control for the Current Political Coalition, we use the variable Party orientation from the same database. It indicates the political orientation for the formed coalition. It assigns value (1) for right-wing, (2) for center, (3) for left-wing. According to Neumayer [67], Dietz et al. [68], and Dunlap et al. [69], there is a link between leftwing parties and being more pro-environmental than right-wing counterparts. Accounting for this link and taking the right-wing as our base value, a positive sign for the party orientation variable is expected.

Finally, whether countries have the scope to invest in new technologies also depends on available funds in countries. The variable Resource Constraints is proxied by several variables to control for the economic context and the scope for initiating renewable policies in countries. Therefore, the GDP per capita will serve as a further control for a country's resource constraints.

\section{Control variables}

Energy price Shrinking fossil fuel sources will increase energy prices. This, in turn, should also increase the incentive to search for alternatives and therefore foster policies supporting renewable energy production. Data on end-user electricity prices in both residential and industrial sectors were collected from the IEA database. The calculated price index was constructed by averaging the price indices for both sectors, similar to Johnstone et al. [27] or Nesta et al. [26].

To control for the structure of the energy production system, we will use the total installed capacity in energy production, the amount of energy produced by renewables, and the share of renewables in total primary energy supply.

All the numeric variables, except dummy and percentages (the nuclear shocks, established democracy, autonomous regions, party orientation, and share of renewable energy) are logged. ${ }^{13}$ For robustness checks, however, we will use both forms of the dependent variables (absolute and logged values).

Table 1 collects the summary statistics of variables, and the additional list of countries and the correlation table can be found in Additional file 1.

\section{Econometric specification}

To test whether nuclear shocks positively correlate with political activity, according to the stylized ACF in Fig. 2, we state the following basic econometric specification:

$$
\begin{aligned}
\operatorname{REP}_{i t}= & \beta_{0}+\boldsymbol{v}^{\prime} \boldsymbol{N}_{i \boldsymbol{t}}+\boldsymbol{\rho}^{\prime} \boldsymbol{R}_{\boldsymbol{i t}}+\boldsymbol{\phi}^{\prime} \boldsymbol{S}_{\boldsymbol{i t}}+\boldsymbol{\Psi}^{\prime} \boldsymbol{P}_{\boldsymbol{i t}}+y_{t} \\
& +\mu_{i}+\epsilon_{i t}
\end{aligned}
$$

with $i=1,2, \ldots, n$ as number of countries, $t=1,2, \ldots$, $T$ as time span, and $\mathrm{REP}_{i t}$ as dependent variable. A constant term is assumed with $\beta_{0}$. The nuclear disaster dummies are summarized in vector $\boldsymbol{N}_{\boldsymbol{i t}}$ with the associated coefficient vector $\boldsymbol{v}$. The controls referring to the ACF are contained in the following vectors: $\boldsymbol{R}_{i t}$ for $R e$ source Constraints with $R_{i t}=$ \{GPD p.c., Total Capacity, Renewables gen., Energy price $\}, S_{i t}$ for Relatively Stable Parameters with $S_{i t}=$ Established Democracies, Autonomous Region\}, and $P_{i t}$ for Current Political Balance of Powers with $\boldsymbol{P}_{\boldsymbol{i t}}=$ \{Party orientation $\}$; the associated coefficients are $v, \rho$, and $\phi$, respectively. For two-way fixed effect models, $y t$ and $\mu i$ denote the time and country fixed effects, respectively.

\section{Procedure}

In a first step, we run linear panel regression models on the pooled sample. Beforehand, we perform several unitroot and cointegration tests. Since the panel as a whole is unbalanced, we draw on the augmented Dickey-Fuller unit-root test (see Additional file 1). ${ }^{14}$ The null hypothesis of the panel containing a unit root can be rejected with a $p$ value of 0.0054 . For cointegration, we run the Kao test and the Pedroni residual cointegration test (see Additional file 1 which we performed using STATA 15.

The analysis begins with LSDV models, Table 2, presented in Eq. 1. These models are applied to test the first hypothesis, whether nuclear accidents exert a positive

\footnotetext{
${ }^{13}$ This transformation smooths the skewness of the data and brings it closer to a normal distribution. It also reduces the influence of extreme values, i.e., possible outliers. Moreover, the estimated coefficients of the so-called log-log-model offer a convenient way for interpretation, as they represent changes measured in elasticities.

${ }^{14}$ In addition, as the dependent variable has no missing values, we add Table 4 in the appendix with additional unit-root tests for robustness.
} 
Table 1 Descriptive statistics (time span 1980-2015)

\begin{tabular}{|c|c|c|c|c|c|c|}
\hline Name & Unit & Obs & Mean & Std_dev & Min. & Max. \\
\hline REPS & Number & 1224 & 1.475 & 1.281 & 0 & 4.625 \\
\hline GDP p. c. & Billion US\$ (2005) & 1152 & 10.22 & 0.443 & 8.535 & 11.42 \\
\hline Total Capacity & Installed MW & 1220 & 9.856 & 2.504 & 0 & 14.87 \\
\hline Renewables gen. & KTOE & 1204 & 8.004 & 1.755 & 1.269 & 11.94 \\
\hline Share of Renewables & $\%$ of total supply & 1204 & 13.05 & 15.59 & 0.0100 & 89.75 \\
\hline Energy price & US\$ per unit (2005) & 1130 & 4.630 & 0.529 & 0 & 5.763 \\
\hline Established Democratic & Number & 1175 & 43.57 & 26.41 & 1 & 85 \\
\hline Autonomous Region & Dummy & 1175 & 0.254 & 0.435 & 0 & 1 \\
\hline Party orientation & Indicator & 1063 & 1.898 & 0.920 & 1 & 3 \\
\hline
\end{tabular}

impact on the number of adopted renewable energy policies, in the aftermath of a nuclear accident. To check the robustness of the results, additional pre-sample mean and binomial regression models are added, presented in Tables 2 and 3. Then, to calculate the effectiveness of the "window of opportunity," we apply a dynamic heterogeneous panel model presented in Table 4. In Table 6, we split the policies into $R \& D$ and diffusion policies to test our third hypothesis, whether we can observe a change in the type of policy measures. We expect that at the beginning of the period under consideration R\&D supporting policy measures should prevail, whereas in later time, diffusionoriented policy should gain importance.

\section{Results}

Table 2 shows the first five models. Using logged values in regression allows us to interpret estimated coefficients as elasticities. ${ }^{15}$ Therefore, we take logs of the dependent variable REP (renewable energy policies). In later models, we use unlogged values when we turn to count data models, since the dependent variable REP is countable.

Model 1 in Table 2 regresses REP on the three dummy variables: Chernobyl, Ibaraki, and Fukushima, which represent the starting point of the periods after the respective nuclear disaster. Simultaneously, we included panel fixed effects (FE) to account for unobserved heterogeneity. ${ }^{16}$ After the accident in Chernobyl in 1986, the average number of effective renewable energy policies increases significantly, which is also the case for the accidents of Ibaraki and Fukushima. Adding resource constraints, i.e., GDP p.c., Total Capacity, Renewables gen., and Energy price as controls in model 2, leaves the significance of the coefficients of the nuclear disaster dummies unchanged, except for the Chernobyl dummy. Concerning the controls, the coefficient of GDP p.c. is significant and positive as to be expected. Countries with a higher per capita income

\footnotetext{
${ }^{15}$ See also footnote 12 for further advantages of logging variables.

${ }^{16}$ The Hausmann tests suggest using a fixed-effect model.
}

should also have the financial capacity to induce a costly green policy change and pass more renewable energy policies. They might be less financially constraint. ${ }^{17}$ Total capacity takes a significantly negative coefficient. If the share in renewable energy production increases, so does the number of renewable energy policies. The control Energy price refers to the standard textbook argument that increasing prices simultaneously increase the attractiveness to invest in new technologies-a relationship that governments try to exploit through passing supportive policy measures. Alternatively, model 3 includes the stable system parameters Established Democracies and Autonomous Region as well as the Balance of Powers indicator variable Party orientation. The coefficient for Established Democracies is positive and significant, indicating that the longer a country has experienced democracy, the more active it is in renewable policymaking. The autonomy of a country also plays a positive role in renewable energy policies. If countries reflect an Autonomous Region in their policymaking, they pass more policy initiatives in renewable energy.

Combining the two groups of constraints, resource (model 2) and political (model 3), introduces high multicollinearity, rendering the estimation inefficient, though consistent. Model 4 reports the respective results; ${ }^{18}$ additionally, year fixed effects are included. Aside from Chernobyl, also Fukushima loses its significance. Only Ibrahaki remains significant. Model 5 replicates the previous model. Instead of the fixedeffects estimator, we use a pre-sample mean (PSM)

\footnotetext{
${ }^{17} \mathrm{GDP}$ p. c. is a blurred proxy for financial constraints of and within a country. With regard to the adoption of green energy technologies, however, access to financial funds is crucial. Because of the risks involved in renewable energy projects and the uncertainty of their returns, as argued by Taghizadeh-Hesary and Yoshino [67], Yoshino et al. [68], or Taghizadeh-Hesary et al. [21], the actual adoption of those technologies hinges on these institutional settings, which, unfortunately, we could not capture in our regressions, because of the lack of a control variable available for all countries.

${ }^{18}$ The variance inflation factors of Chernobyl and Ibaraki are far beyond 10 .
} 
Table 2 Linear regression models

\begin{tabular}{|c|c|c|c|c|c|}
\hline \multicolumn{6}{|l|}{ Dep. variable: In(REP) } \\
\hline & (1) & (2) & (3) & (4) & (5) \\
\hline Variables & FE & FE & FE & LSDV & PSM \\
\hline \multirow[t]{2}{*}{ Chernobyl } & $0.399^{* * *}$ & 0.116 & 0.109 & 0.110 & 0.094 \\
\hline & $(0.075)$ & $(0.109)$ & $(0.165)$ & $(0.189)$ & $(0.093)$ \\
\hline \multirow[t]{2}{*}{ Ibaraki } & $1.609^{* * *}$ & $1.070^{* * *}$ & $1.091^{* * *}$ & $1.225^{* * *}$ & $1.035^{* * *}$ \\
\hline & $(0.108)$ & $(0.151)$ & $(0.236)$ & $(0.159)$ & $(0.137)$ \\
\hline \multirow[t]{2}{*}{ Fukushima } & $0.728^{* * *}$ & $0.356^{* * *}$ & $0.356^{* *}$ & -0.135 & $0.269^{* * *}$ \\
\hline & $(0.068)$ & $(0.083)$ & $(0.155)$ & $(0.126)$ & $(0.084)$ \\
\hline \multirow[t]{2}{*}{ GDP p.c. (in logs) } & & $1.346^{* * *}$ & & 0.291 & $0.574^{* *}$ \\
\hline & & $(0.430)$ & & $(0.183)$ & $(0.274)$ \\
\hline \multirow[t]{2}{*}{ Total Capacity Mw (in logs) } & & $-0.112^{* * *}$ & & $-0.043^{* *}$ & $-0.058^{* *}$ \\
\hline & & $(0.032)$ & & $(0.019)$ & $(0.027)$ \\
\hline \multirow[t]{2}{*}{ Renewables gen. (in logs) } & & $0.205^{*}$ & & 0.051 & $0.165^{* *}$ \\
\hline & & $(0.115)$ & & $(0.038)$ & $(0.069)$ \\
\hline \multirow[t]{2}{*}{ Energy price (in logs) } & & $0.525^{* * *}$ & & $0.223^{* * *}$ & $0.542^{* * *}$ \\
\hline & & $(0.159)$ & & $(0.072)$ & $(0.152)$ \\
\hline \multirow[t]{2}{*}{ Established Democratic } & & & $0.045^{* *}$ & $0.038^{* * *}$ & $0.020^{* * *}$ \\
\hline & & & $(0.018)$ & $(0.008)$ & $(0.005)$ \\
\hline \multirow[t]{2}{*}{ Autonomous Region } & & & 0.221 & 0.131 & 0.150 \\
\hline & & & $(0.281)$ & $(0.104)$ & $(0.172)$ \\
\hline \multirow[t]{2}{*}{ Party orientation $=\mathrm{C}$} & & & -0.069 & -0.031 & -0.024 \\
\hline & & & $(0.079)$ & $(0.065)$ & $(0.055)$ \\
\hline \multirow[t]{2}{*}{ Party orientation $=\mathrm{L}$} & & & -0.034 & 0.031 & 0.017 \\
\hline & & & $(0.063)$ & $(0.037)$ & $(0.069)$ \\
\hline \multirow[t]{2}{*}{ Pre-sample Mean } & & & & & 0.468 \\
\hline & & & & & $(0.335)$ \\
\hline \multirow[t]{2}{*}{ Constant } & $0.282^{* * *}$ & $-15.834^{* * *}$ & $-1.169^{* *}$ & $-4.591^{* * *}$ & $-9.145^{* * *}$ \\
\hline & $(0.077)$ & $(3.517)$ & $(0.547)$ & $(1.692)$ & $(2.509)$ \\
\hline Observations & 1,224 & 1,057 & 1,063 & 955 & 955 \\
\hline$R^{2}$ & 0.773 & 0.821 & 0.800 & 0.857 & \\
\hline$R^{2}$ adj. & 0.772 & 0.820 & 0.799 & 0.845 & \\
\hline Number of countries & 34 & 33 & 33 & 32 & 32 \\
\hline Year dummies & No & No & No & Yes & No \\
\hline Fixed effects & Yes & Yes & Yes & Yes & No \\
\hline
\end{tabular}

Note: All regressions include robust standard errors.

Standard errors in parentheses

${ }^{* * *} p<0.01,{ }^{* *} p<0.05,{ }^{*} p<0.1$

approach. ${ }^{19}$ With all controls included, Ibaraki and Fukushima remain significant and positive.

In the next step, we concentrate on the fact that the dependent variable REP is count data. Table 3 reports three count data models. Because of overdispersion, we use negative binomial regression instead of Poisson

\footnotetext{
${ }^{19}$ The advantage of the PSM estimator is that the loss of information is less compared to the Hausman et al. [69] fixed-effect estimator, which simply demeans all variables wiping out a major part of level effects. In addition, the PSM estimator has better finite sample properties [26].
}

regression..$^{20}$ In all models, the resource constraint variables take the same sign as in the previous models and are significant. In model 7 , we alternatively use the share of renewable energy production instead of the absolute amount of production as in the remaining models. ${ }^{21} \mathrm{All}$ coefficients of the system parameters which remain significant

\footnotetext{
${ }^{20} \mathrm{An}$ LR-test rejects the null of a unique parameter $\lambda$ for the first two moments.

${ }^{21}$ Due to multicollinearity, we did not include both variables simultaneously into regressions.
} 
Table 3 Count data regressions. Dep. variable: REP

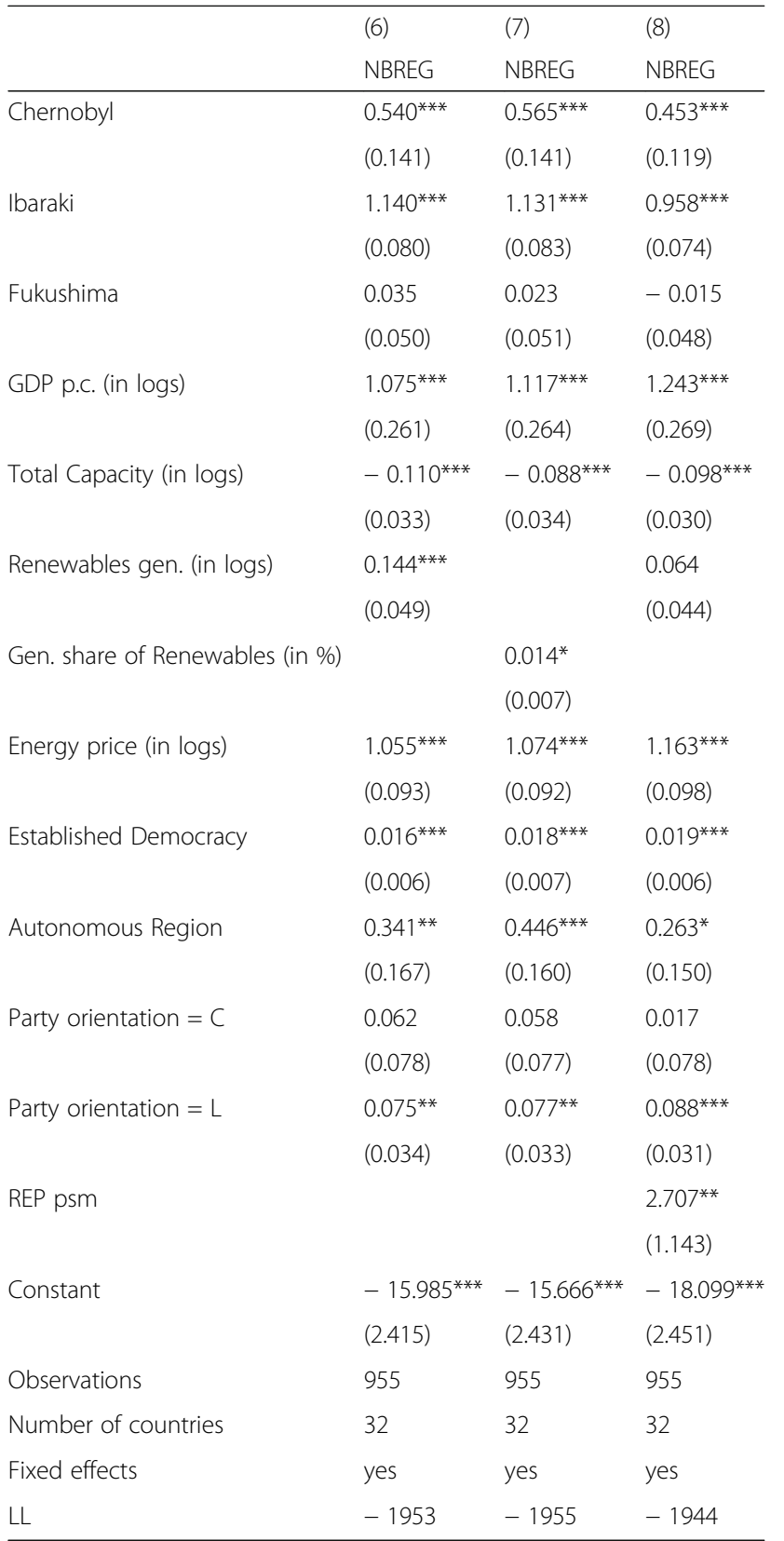

Note: All regressions include robust standard errors

Standard errors in parentheses

${ }^{* * *} p<0.01,{ }^{* *} p<0.05,{ }^{*} p<0.1$

also keep their sign. The party position for left-wing coalitions is throughout positive (Party orientation $=\mathrm{L}$ ). ${ }^{22}$ In line with the literature, left-wing coalitions in governments tend to pass significantly more renewable energy policies than out baseline, i.e., right-wing parties [67-69].

Models 6 to 8 use the standard fixed-effects estimator of Hausman et al.

\footnotetext{
${ }^{22}$ For ease of reading, we recoded the variable Party orientation as in the following: left-wing $(=\mathrm{L})$, right-wing $(=\mathrm{R})$, and center $(=\mathrm{C})$.
}

Table 4 Dynamic heterogeneous panel regressions. Dep. variable: In (Rep)

\begin{tabular}{|c|c|c|c|}
\hline & (9) & (10) & (11) \\
\hline Variables & DFE & DFE & DFE \\
\hline \multirow[t]{2}{*}{ Chernobyl } & -0.166 & -0.367 & -0.331 \\
\hline & $(0.253)$ & $(0.281)$ & $(0.250)$ \\
\hline \multirow[t]{2}{*}{ Ibaraki } & $0.702^{* * *}$ & $0.462^{*}$ & $0.553^{*}$ \\
\hline & $(0.222)$ & $(0.261)$ & $(0.303)$ \\
\hline \multirow[t]{2}{*}{ Fukushima } & $2.283^{* * *}$ & $1.858^{* * *}$ & $1.502^{* * *}$ \\
\hline & $(0.323)$ & $(0.303)$ & $(0.244)$ \\
\hline \multirow[t]{2}{*}{ GDP p.c. (in logs) } & & $1.456^{* *}$ & 1.381 \\
\hline & & $(0.729)$ & $(0.961)$ \\
\hline \multirow[t]{2}{*}{ Total Capacity (in logs) } & & -0.084 & -0.070 \\
\hline & & $(0.082)$ & $(0.070)$ \\
\hline \multirow[t]{2}{*}{ Renewables gen. (in logs) } & & 0.176 & 0.195 \\
\hline & & $(0.182)$ & $(0.139)$ \\
\hline \multirow[t]{2}{*}{ Energy price (in logs) } & & & 0.470 \\
\hline & & & $(0.342)$ \\
\hline \multirow[t]{2}{*}{ Autonomous Region } & & & -0.172 \\
\hline & & & $(0.274)$ \\
\hline \multirow[t]{2}{*}{ Party orientation } & & & -0.093 \\
\hline & & & $(0.084)$ \\
\hline \multirow[t]{2}{*}{$\mathrm{EC}$} & $0.097^{* * *}$ & $0.117^{* * *}$ & $0.141^{* * *}$ \\
\hline & $(0.014)$ & $(0.016)$ & $(0.021)$ \\
\hline \multirow[t]{2}{*}{ Nuc accidents } & $0.127^{* * *}$ & $0.132^{* * *}$ & $0.144^{* * *}$ \\
\hline & $(0.028)$ & $(0.031)$ & $(0.042)$ \\
\hline \multirow[t]{2}{*}{ Gen. share of Renewables } & & -0.000 & 0.000 \\
\hline & & $(0.006)$ & $(0.006)$ \\
\hline \multirow[t]{2}{*}{ Constant } & -0.029 & $1.717^{* *}$ & $2.257^{*}$ \\
\hline & $(0.020)$ & $(0.797)$ & $(1.207)$ \\
\hline Observations & 1224 & 1104 & 955 \\
\hline Number of countries & 34 & 34 & 32 \\
\hline$R^{2}$ adj. & 0.262 & 0.275 & 0.282 \\
\hline
\end{tabular}

[69], and model 8 applies the pre-sample mean (PSM) estimator by Blundell et al. [70] and uses information before the actual years of investigation; in our case, the pre-sample mean is calculated from the years 1975 to $1979 .{ }^{23}$ As the PSM coefficient in model 8 shows, there is significant unobserved heterogeneity across countries. Moreover, models 7 and 8 include year fixed effects. ${ }^{24}$ The coefficient of Autonomous Regions becomes

\footnotetext{
${ }^{23}$ In contrast to the remaining variables, the policy measure variable (Rep) contains a longer time span, starting in 1975. This allows calculating a pre-sample mean without loss of information.

${ }^{24}$ The inclusion of year dummies takes away the significance of some of the control variables.
} 
significant in all three models. As theoretical anticipated, coalition positioning, left-wing parties seem to pass more environment friendly when compared to right-wing coalitions. The coefficients of main interest, i.e., the coefficients of the nuclear shocks remain always positive and significant except for Fukushima.

One of the caveats in the regressions above is the treatment of the nuclear disaster dummies. Before the disaster, the respective dummy is 0 , after the accident, it remains 1 till the end of the observed time span. One may argue that the effect of a nuclear disaster opening up a window of opportunity for a policy change is not lasting eternally, but fades out after some time. The length of effectiveness of a shock, we identify via Dynamic Heterogeneous Panel Models (DHPM). The technical description can be consulted in the Appendix. This technique is based on an autoregressive distributed lag model, it includes an error correction, and allows addressing endogeneity issues. In a nutshell, it estimates a long-run dynamic to which the system returns after an exogenous shock, and additionally, it estimates short-run effects.

In models 9 to 11 in Table 4, we report three dynamic heterogeneous panel models. As the Hausmann test suggests, we apply dynamic fixed-effects estimation. The long-run variables contain the same variables as in previous models except for Established Democracies, because all three models calculate a long-run trend with which the variable Established Democracies is in conflict due to multicollinearity. For the short-run, we include nuclear shock dummies, although in an aggregated manner by adding up all three dummy variables. Because the short-term variables are differenced in this errorcorrection model, dummy variables were infeasible; therefore, we aggregated the three accidents and built a single variable collecting the three accidents. ${ }^{25}$ The longrun coefficients indicate a persistently positive and significant effect on the number of renewable policies only for Ibaraki and Fukushima. The short-run analysis, illustrated in the lower part of this table, also suggests significantly positive effects of nuclear disasters on renewable energy policies. Equivalently, nuclear disasters correlate in the short run positively with the number of renewable energy policies.

The statistic of this table, in which we are particularly interested, is the so-called error correction term (EC). The EC coefficient is significant and ranges from 0.097 to 0.14 . This indicates that serial correlation is present in our data. Unless we correct for serial correlation, this

\footnotetext{
${ }^{24}$ The inclusion of year dummies takes away the significance of some of the control variables.

${ }^{25}$ Including further variables in the short-run part of the models prevents models to converge.
}

leads to inconsistent estimates. Since the EC coefficient reports the required error correction, its interpretation is straightforward. It denotes the persistence of shocks. After a shock, the system returns to the long-run equilibrium after about $1 / 0.141=7$ years. In other words, a shock such as a nuclear disaster, which increases political activity, fades out after about 7 years. This result can be interpreted as the length of the window of opportunity. These results we use for a further robustness check. Again, we rerun the preferred models form above while changing the nuclear accident dummy variables to windows. That is, before the accident the dummy remains 0 , after the accident, it takes the value 1 for 7 years to finally return to 0 . The results are presented in Table 5 . The treatment of the nuclear accident dummies also allows us to include year dummies, because multicollinearity becomes less prevalent. Hence, model 12 reports the results of a two-way fixed-effects model with a 7year window for each nuclear accident dummies. All three dummies are positive and significant, which supports the hypothesis that more renewable energy policies are passed after a nuclear accident.

In model 13, we include all control variables, which makes the Chernobyl dummy lose significance. Taking the count data quality of the dependent variable into account, as done in model 14, Chernobyl remains insignificant, whereas the Ibaraki and Fukushima dummies are positive and significant. The control variables keep their signs, if significant. Hence, also with a window of 7 years, which we inferred from the dynamic heterogeneous panel regressions in Table 4, we still observe that nuclear accidents have a significant effect on political activity in countries. To check for robustness, we additionally tried a 5-year (model 15) and a 9-year (model 16) window for the nuclear shock dummies. Model 15 provides less explanatory power comparing the $R^{2}$ values between this model and model 13. Model 16 generates the same goodness of fit as model 13; in other words, it does not add more information. Hence, we pick model 13 as the preferred model being in line with the PMG estimations in Table 4.

Except for Chernobyl, the results of our regression models suggest a robust correlation between nuclear accidents and renewable energy policies. The fact that no significant effect, despite the severity of the nuclear accident in Chernobyl, could be detected may have several reasons: first, the large geographical distance and the different type of reactor used in Ukraine compared to those used in Western Europe or in the USA [61]. Second, it could be the restricted technological opportunities in 1986. Renewable energies could not be introduced as a solution, after the accident, owing to their immaturity level at the time and the fact that they could not maintain a stable and sufficient energy supply [71]. 
Table 5 Windows. Dep. variable: In(REP) for LSDV and REP for NBREG

\begin{tabular}{|c|c|c|c|c|c|}
\hline & (12) & (13) & (14) & (15) & (16) \\
\hline Variables & LSDV & LSDV & NBREG & LSDV & LSDV \\
\hline \multirow[t]{2}{*}{ Chernobyl } & $0.333^{* * *}$ & -0.152 & 0.375 & -0.165 & -0.049 \\
\hline & $(0.116)$ & $(0.162)$ & $(0.363)$ & $(0.173)$ & $(0.199)$ \\
\hline \multirow[t]{2}{*}{ Ibaraki } & $2.044^{* * *}$ & $1.009^{* * *}$ & $2.051^{* * *}$ & $0.877^{* * *}$ & $1.074^{* * *}$ \\
\hline & $(0.116)$ & $(0.240)$ & $(0.352)$ & $(0.276)$ & $(0.320)$ \\
\hline \multirow[t]{2}{*}{ Fukushima } & $2.710^{* * *}$ & $1.200^{* * *}$ & $2.405^{* * *}$ & $1.200^{* * *}$ & $1.200^{* * *}$ \\
\hline & $(0.116)$ & $(0.309)$ & $(0.392)$ & $(0.334)$ & $(0.334)$ \\
\hline \multirow[t]{2}{*}{ GDP p.c. (in logs) } & & 0.291 & $0.848^{* * *}$ & 0.291 & 0.291 \\
\hline & & $(0.183)$ & $(0.266)$ & $(0.419)$ & $(0.419)$ \\
\hline \multirow[t]{2}{*}{ Total Capacity Mw } & & $-0.043^{* *}$ & $-0.111^{* * *}$ & -0.043 & 0.043 \\
\hline & & $(0.019)$ & $(0.032)$ & $(0.027)$ & $(0.027)$ \\
\hline \multirow[t]{2}{*}{ Renewables gen. (in KTOE) } & & 0.051 & $0.093^{*}$ & 0.051 & 0.051 \\
\hline & & $(0.038)$ & $(0.051)$ & $(0.113)$ & $(0.113)$ \\
\hline \multirow[t]{2}{*}{ Energy price (in logs) } & & $0.223^{* * *}$ & $0.591^{* * *}$ & 0.223 & 0.223 \\
\hline & & $(0.072)$ & $(0.120)$ & $(0.143)$ & $(0.143)$ \\
\hline \multirow[t]{2}{*}{ Established Democratic } & & $0.038^{* * *}$ & -0.002 & $0.038^{* * *}$ & $0.038^{* * *}$ \\
\hline & & $(0.008)$ & $(0.007)$ & $(0.010)$ & $(0.010)$ \\
\hline \multirow[t]{2}{*}{ Autonomous Region } & & 0.131 & 0.227 & 0.131 & 0.131 \\
\hline & & $(0.104)$ & $(0.150)$ & $(0.267)$ & $(0.267)$ \\
\hline \multirow[t]{2}{*}{ Party orientation $=\mathrm{C}$} & & -0.031 & 0.071 & -0.031 & -0.031 \\
\hline & & $(0.065)$ & $(0.072)$ & $(0.059)$ & $(0.059)$ \\
\hline \multirow[t]{2}{*}{ Party orientation $=\mathrm{L}$} & & 0.031 & $0.066^{*}$ & 0.031 & 0.031 \\
\hline & & $(0.037)$ & $(0.034)$ & $(0.065)$ & $(0.065)$ \\
\hline \multirow[t]{2}{*}{ Constant } & $0.313^{* * *}$ & $-4.591^{* * *}$ & $-10.105^{* * *}$ & -4.591 & -4.591 \\
\hline & $(0.082)$ & $(1.692)$ & $(2.497)$ & (3.759) & (3.759) \\
\hline Observations & 1,224 & 955 & 955 & 955 & 955 \\
\hline$R^{2}$ & 0.837 & 0.857 & & 0.837 & 0.857 \\
\hline Number of countries & 34 & 32 & 32 & 32 & 32 \\
\hline Year dummies & Yes & Yes & Yes & Yes & Yes \\
\hline Fixed effects & Yes & Yes & Yes & Yes & Yes \\
\hline Window (years) & 7 & 7 & 7 & 5 & 9 \\
\hline LL & & & -1895 & & \\
\hline
\end{tabular}

Standard errors in parentheses

${ }^{* * *} p<0.01,{ }^{* *} p<0.05,{ }^{*} p<0.1$

Taking the historicity of technical change into account, we now test whether the type of policy changes over time. As argued above, while technological opportunities, in terms of green technologies, were limited in the 1980 s, it seems straightforward to pass R\&D-oriented policies. With increasing technological progress, diffusion-oriented policies should gain in importance. Having the opportunity to decompose our dependent variable from being an aggregated index to single policy types, we may shed light on the kind of policies introduced after the respective nuclear accidents. We decompose the dependent variable (REP) into two categories: policies with an explicit focus on R\&D and those designed to boost the diffusion of renewable energy production technologies. We hypothesize that after an early accident like Chernobyl, an increase in policies supporting research and development should occur.

Conversely, we would expect that after Ibaraki and Fukushima, diffusion policies should have prevailed.

\section{$R \& D$ versus diffusion-oriented policies}

Table 6 documents the results for the two types of renewable policy measures. Model 17 and 18 regress the number of R\&D-oriented policies on the nuclear dummies and 
the controls, respectively. The dummy for the Chernobyl accident is insignificant, the dummies for Ibaraki and Fukushima significantly positive in model 17 . With the controls, as used in the previous models, this does not change. And an increase in R\&D policies, to foster the development of renewable energy technologies, can only be detected after Ibaraki and Fukushima. Note that both models 17 and 18 contain a full set of year and country dummies. Moreover, the calculations were exerted with a 7 -year window for the nuclear accident dummies. The preferred model, according to a likelihood-ratio and a Wald test, respectively, is model 18 . The full model renders a statistically significant improvement in model fit compared to the nested model 17.

Models 19 and 20 perform the same exercise using the number of diffusion-oriented renewable energy policies. Including year and country dummies in addition to 7-year windows as nuclear accident dummies, the cross-correlation between the nuclear accident dummies and the number of active, diffusionoriented policies renders all three nuclear dummies positive and significant. Hence, an increase in diffusion-oriented policies emerged after Chernobyl. However, when including the controls, which all have the expected signs in case they are significant, the coefficient of the Chernobyl dummy loses its significance. We also performed post estimation tests such as a likelihood-ratio and a Wald test: model 20 appears to be a better fit than model 19 and the coefficients of the added control variables are significantly different from zero, indicating that model 20 is more informative. In sum, we could not identify that R\&Doriented policies lose in importance, while diffusionoriented policies gain in importance.

Table 6 R\&D and diffusion policies

\begin{tabular}{|c|c|c|c|c|}
\hline & (17) & (18) & (19) & (20) \\
\hline Variables & NBREG (R\&D) & NBREG (R\&D) & NBREG (DI) & NBREG (DI) \\
\hline \multirow[t]{2}{*}{ Chernobyl } & 0.511 & 0.409 & $0.861^{* * *}$ & 0.204 \\
\hline & $(0.422)$ & $(0.498)$ & $(0.261)$ & $(0.276)$ \\
\hline \multirow[t]{2}{*}{ Ibaraki } & $2.209^{* * *}$ & $2.076^{* * *}$ & $2.900^{* * *}$ & $1.616^{* * *}$ \\
\hline & $(0.351)$ & $(0.511)$ & $(0.227)$ & $(0.274)$ \\
\hline \multirow[t]{2}{*}{ Fukushima } & $2.693^{* * *}$ & $2.440^{* * *}$ & $3.584^{* * *}$ & $1.852^{* * *}$ \\
\hline & $(0.344)$ & $(0.559)$ & $(0.225)$ & $(0.294)$ \\
\hline \multirow[t]{2}{*}{ GDP p.c. (in logs) } & & 0.045 & & $1.166^{* * *}$ \\
\hline & & $(0.541)$ & & $(0.262)$ \\
\hline \multirow[t]{2}{*}{ Total Capacity Mw } & & 0.024 & & $-0.129^{* * *}$ \\
\hline & & $(0.074)$ & & $(0.030)$ \\
\hline \multirow[t]{2}{*}{ Renewables gen. (in KTOE) } & & 0.057 & & 0.046 \\
\hline & & $(0.107)$ & & $(0.049)$ \\
\hline \multirow[t]{2}{*}{ Energy price (in logs) } & & 0.346 & & $0.814^{* * *}$ \\
\hline & & $(0.248)$ & & $(0.115)$ \\
\hline \multirow[t]{2}{*}{ Autonomous Region } & & 0.234 & & $0.434^{* * *}$ \\
\hline & & $(0.237)$ & & $(0.140)$ \\
\hline \multirow[t]{2}{*}{ Party orientation $=\mathrm{C}$} & & $0.325^{* *}$ & & 0.034 \\
\hline & & $(0.130)$ & & $(0.070)$ \\
\hline Party orientation $=\mathrm{L}$ & & $0.109 *(0.059)$ & & $0.072^{* *}(0.031)$ \\
\hline \multirow[t]{2}{*}{ Constant } & -0.176 & -2.843 & 0.081 & $-13.561^{* * *}$ \\
\hline & $(0.341)$ & $(5.278)$ & $(0.227)$ & $(2.552)$ \\
\hline Observations & 1296 & 955 & 1224 & 955 \\
\hline Year dummies & Yes & Yes & Yes & Yes \\
\hline Fixed effects & Yes & Yes & Yes & Yes \\
\hline Window $=7$ years & Yes & Yes & Yes & Yes \\
\hline $\mathrm{LL}$ & -1141 & -936.9 & -2423 & -1961 \\
\hline
\end{tabular}




\section{Discussion}

Overall, we observe an elevated political activity in renewable energy support across countries after nuclear accidents. The results, however, have to be put into perspective. In Table 2, only models 1 and 5 pass the specification test of an omitted variable bias, models 2,3 , and 4 do not. In addition, model 4 suffers from high multicollinearity. Hence, model 5 is the preferred model supporting the hypothesis that after external shocks policy activity increases-as far as Ibaraki and Fukushima are concerned.

Using count data models (Table 3), the Chernobyl dummy becomes significant and the Fukushima dummy insignificant. Distinguishing between a short-run and a long-run perspective (Table 4), the DHP-models maintain the significance of the dummies for Ibaraki and Fukushima. As these regression models contain and error correction, we can calculate the average time span of a "window of opportunity," which amounts to about 7 years. Considering this information in previous regressions, as reported in Table 5, the correct version in model 14 is the preferred model.

It advocates again that there is a significantly positive effect on policy activities after the nuclear accidents in Ibaraki and Fukushima.

The only exception is the effect for Chernobyl, which is mixed. Only in a few models, we could identify a significant correlation between the shock and policy measures. Hence, there is no robust evidence in the case of Chernobyl. There could be various explanations for this result. In 1979, before the starting year of our data set, there had already been a nuclear accident on Three Mile Island, which was rated 5 on the INES scale [72]. Hence, the time span between Three Mile Island and Chernobyl is only 7 years, the length of the window of opportunity we calculated and consequently, the differential impacts of both accidents have become unidentifiable. This is in line with Nohrstedt [33] arguing that some countries such as Sweden responded immediately after Three Mile Island by initiating renewable energy programs so that later on, policy makers were already alert and unlikely to take additional measures as a response to the accident in Chernobyl.

Another angle for explaining the aforementioned effect of Chernobyl disaster is the public "perception of need" for nuclear energy, as argued by Bisconti [18]. In 1980s, renewable energy technologies were considered complementary energy sources alongside nuclear energy, rather than a reliable substitution [71]. Therefore, the public saw a need for nuclear energy and thus the impact of relevant accidents on their attitudes was low. For instance, the decline in public acceptance for nuclear energy in the USA faded out only 3 months after the Chernobyl accident [18], while in the UK, the level of support in 1987 was back to its initial values as before the accident $[73,74]$. This, in turn, was translated in a lower activity on political level [75].

A further explanation could be that the index is blurred by aggregation. Renewable energy policies are quite diverse. Some focus on the development of new technologies, and others focus on the diffusion of renewable energy technologies. The state of the art of renewable energy technologies was certainly different at the time of each accident. One might expect that more $R \& D$ policies should be identifiable after Chernobyl. Likewise, diffusion-oriented policies should be more frequent after Fukushima, because of the advancements in renewable energy technologies. While there is evidence for an increase in both policy types after Fukushima and Ibaraki, no strong empirical support was found for either of the policies after Chernobyl. The two preferred models in Table 6, model 18 for R\&D-oriented policies and model 20 for diffusion-oriented policies, do not provide empirical evidence to support this hypothesis.

With respect to the theoretical foundation, the conceptual model, chosen from communication science, describes the underlying mechanism of policy change. The architecture of this concept consists of several dimensions. It contains a micro, a meso, and a macro perspective to trace individual behavior via the formation of subgroups to coalitions, which finally take influence on the political decision-making process. With the data at hand, the empirical exercise cannot give any insights neither on the micro nor on the meso level. We assume the aggregated elements of the system as given and thus construct the context in which external shocks unfold either leading to policy change or not. As claimed beforehand, this paper is just a first attempt to quantify the most general propositions of the ACF. Certainly, it needs a more in-depth analysis both of the theoretical as well as of the empirical perspective.

With respect to the empirical layout, a further weakness of the analysis roots in the discrepancy between the frequency of events in the political decision-making process and the frequency in the data. Political change is discontinuous and occurs often within a shorter time than associated with annual data. Hence, we cannot claim to provide evidence on the complete causal chain from nuclear accidents to actual policy change. For this, we would require data of higher frequency (e.g., monthly). This is why most studies concentrate on case studies, because for a country-level comparison, such kind of meticulous investigation remains tedious [33, 61, 76] but should be pursued in future research.

\section{Conclusion}

The empirical study presented here is a first step toward quantifying the effect of external shocks, i.e., nuclear 
disasters, on political activity in renewable energy policymaking. As for the theoretical foundation, we use the Advocacy Coalition Framework (ACF) that describes the process of how policy change comes along. The ACF in nature focuses on the formation of advocacy coalitions, beliefs, and coordination within and among coalitions $[52,53,77]$. With the introduction of the policy network approach and social network analysis [78-80], the interest has gradually shifted from solely investigating the role of beliefs [34] to the analysis of coordination mechanisms [80-82]. Partially, this is due to methodological advancements such as the introduction of network analysis into the ACF.

In this work, we suggest a frequentist perspective to the ACF. From a methodological point of view, it is not surprising that the majority of the research work applies qualitative techniques, mostly case studies [35-41], because of the inherent complexity of the political process. This challenge becomes even more complex when it comes to trans-regional comparisons. On these grounds, we tried to add a first, modest, cross-country quantitative view on the ACF. Hence, the contribution of this paper is less in elaborating on micro or meso aspects, which still do require a lot more of research to better understand the process of policy change, but rather provide a first step in applying a quantitative approach to compare political systems across countries based on the main concepts of the ACF. For these reasons, we had to simplify the ACF to a major extent, neglecting many important determinants usually considered within this framework. ${ }^{26}$

In doing this, we give a complementary perspective on the ACF when applying a quantitative approach as we believe that a quantitative replenishment may facilitate detecting commonalities and dissimilarities in policy change across policy systems and regions, i.e., countries. As the results suggest, the aftermath of external shocks (nuclear disasters) points toward an increase in green policy initiatives across countries-evidence that is in line with our main hypothesis that such external shocks function as "focusing events" giving a little push toward green policy change.

A further observation in terms of commonalities, although this concerns the controls of our regression models we did not focus on, yet, it further advocates a quantitative inductive approach: we identified a positive correlation between left-wing parties (beliefs) and an increase in green policy activities. Observing such kind of, to our minds, unexpected commonality is a further advantage of applying a quantitative approach to the ACF. It was an intriguing research question to investigate

\footnotetext{
${ }^{26}$ See, e.g., Sabatier and Weible $[53,77]$ or Sabatier and Jenkins-Smith [52] for all the specificities in the ACF and its research fields.
}

whether there is an explanation to this correlation or whether it simply is a methodological artifact. This approach nonetheless helps disclose new research avenues.

With respect to the regressions we performed in this study, i.e., OLS, LSDV, negative binomial, pre-sample mean, and dynamic panel regressions, and given the fact that they point toward a positive correlation between nuclear accidents and a subsequent increase in renewable energy policies, we emphasize that we do not claim that these correlations describe a causal chain of political reactions induced by external shocks. We simply tried to find the consequential correlation which should be observable after external shocks to support the hypothesis that external shocks, i.e., nuclear accidents, serve as a focusing event, after which the number of green policies adopted by countries has increased. Solely for Chernobyl, we could not detect robust evidence, although one would expect that energy policies should have surged dramatically thereafter.

In future research, we should consider additional determinants as substantiated, e.g., in the policy change literature [76], such as the role of political entrepreneurs being the crucial agents of change [83]. Or in a similar vein, the impetus of political institutions to the extent to which they either are conducive or inhibiting policy change [76]. From a modeling perspective, the role of mass media in setting policy agendas must be included [84], since mass media not only influence public opinion but also attract the attention of policy makers to relevant topics. The holistic picture, as insinuated with the ACF, should help understand the mechanisms that bring along policy change.

To derive explicit policy implications from this empirical exercise seems futile, because external shocks, especially nuclear accidents, are no favorable events people would be longing for in order to induce policy change. It rather is a further evidence to a very sad revelation that policy makers as much as mankind apparently need disasters to make a change.

\section{Nomenclature}

ACF Advocacy Coalition Framework

ARDL Autoregressive distributive lag model

DHPM Dynamic heterogeneous panel model

IAEA International Atomic Energy Agency

INES International Nuclear Event Scale

OIM Observed Information Matrix

REP Renewable energy policies

SFE Static fixed effect

DFE Dynamic fixed effects

EC Error correction term

IEA International Energy Agency

LSDV Least square dummy Variable

MG Mean group 
PMG Pooled mean group model

PSM Pre-sample mean

\section{Appendix}

A. Dynamic heterogeneous panel models

The general model of the dynamic heterogeneous panel estimation, which will be presented here, is discussed by [75-77].

\section{B. General model}

The general model assumes that the input data on time period $t=1,2, \ldots, T$ and across section groups $i=1$, $2, \ldots, N$ can be estimated by an autoregressive distributive lag model $\operatorname{ARDL}\left(p, q, . ., q_{k}\right)$ :

$$
y_{i t}=\sum_{j=1}^{p} \lambda_{i j} y_{i, t-j}+\sum_{j=0}^{q} \delta_{i j}^{\prime} X_{i, t-j}+\mu_{i}+\epsilon_{i t}
$$

for $i=1,2, \ldots, N$ and $t=1,2, \ldots, T$. The error correction speed of adjustment parameter is expressed as in the following:

$$
\begin{aligned}
\Delta y_{i t}= & \phi_{i}\left(y_{i, t-1}-\beta_{i}^{\prime} X_{i t}\right)+\sum_{j=1}^{p-1} \lambda_{i j}^{*} \Delta y_{i, t-1} \\
& +\sum_{j=0}^{q-1} \delta_{i j}^{\prime *} \Delta X_{i, t-1}+\mu_{i}+\epsilon_{i t}
\end{aligned}
$$

where $X_{i t}$ is the $(\mathrm{k} \times 1)$-vector of explanatory variables, $\lambda_{i j}$ a scalar of constants, $\delta_{i t}$ the $\mathrm{k} \times 1$ coefficient vectors, $\mu \mathrm{i}$ the group-specific effect, and $\varepsilon_{i t}$ the group-specific effect. As $T$ is large enough, each group can be estimated separately. The variables in Eq. 2 are cointegrated I(1) and the error term is an $\mathrm{I}(0)$ process for all $i$; therefore, the error correction equation can be reparametrized as follows:

$$
\begin{aligned}
\phi_{i} & =-\left(1-\sum_{j=1}^{p} \lambda_{i j}\right) \\
\beta_{i}^{\prime} & =\sum_{j=0}^{q} \delta_{i j}, \\
\lambda_{i j}^{*} & =-\sum_{m=j+1}^{p} \lambda_{i m} j=1,2, \ldots, p-1
\end{aligned}
$$

and

$$
\delta_{i j}^{*}=-\sum_{m=j+1}^{q} \delta_{i m} j=1,2, \ldots, q-1
$$

assuming that the ARDL model in Eq. 2 is stable in that the roots of lie outside the unit circle, ensuring that the error-correcting speed of adjustment term $\phi \mathrm{i}<0$. This implies that there is a long-run relationship between the dependent variable $Y_{i t} \mathrm{t}$ and the regressors $X_{i t}$. It is calculated as

$$
y_{i t}=-\left(\beta_{i}^{\prime} / \phi_{i}\right) x_{i t}+\eta_{i t}
$$

\section{Estimators for Heterogeneous slopes}

Micro panels with small time series ( $\mathrm{T}$ ) and a large number of cross-section observations $(\mathrm{N})$ usually rely on either fixed effects, random effects, static fixed effect (SFE), or a combination of those [78]. As Pesaran and Smith [79] point out, with large $T$, such traditional estimators may generate inconsistent results, because they assume homogeneous slopes among panel units. ${ }^{27}$

In general, the assumption of homogeneous slope parameters does not hold in dynamic panel data with large $\mathrm{T}$ and large $\mathrm{N}[80,81]$. With $\mathrm{T}$ increasing, more attention has to be paid to issues such as serial correlation caused by shocks, whether temporary or persistent, as this may lead to biased estimation results. Pesaran and Smith [79], for example, show that GMM estimation in dynamic panel models has inconsistent long-term coefficients, when actual slopes are heterogeneous. For these reasons, we apply the pooled mean group model (PMG) introduced by Pesaran and Smith [79] and Blackburne and Frank [75].

The PMG model distinguishes short-run and long-run effects. It allows short-term coefficients, the convergence adjustments speed (the coefficient of error correction term), and the error variances to differ across countries. However, it assumes homogeneity of slope parameters across countries on the long run (Blackburne and Frank [75]).

The PMG estimator is a combination of the mean group (MG) and the dynamic fixed-effects (DFE) models. Whereas the MG model averages the slope coefficients of separate regressions by panel-unit, the DFE model is similar to the one-way fixed effects or least square dummy variable (LSDV) approach allowing for heterogeneous intercepts but homogeneous slope coefficients. In contrast to the fixed-effects model, the DFE approach also distinguishes between short-run and longrun effects. There are various reasons to assume common long-run coefficients across OECD countries. OECD countries have access to common technologies and similar policy trends. Popp et al. [82], for example, put forward that the Kyoto protocol played a fundamental role in shaping the investment in renewable energy capacity at the country level during 1979 to 2008; all member countries were exposed to the same international pressure to introduce further environmental regulations. The positive effect of renewable energy

${ }^{27}$ Compare Pesaran et al. [77]. 
policies, induced by the Kyoto protocol, was also identified by Nesta et al. [25].

Conversely, assuming the speed of convergence across countries to be similar is rather implausible, as countries' institutional frames differ. Together with the fact that our data set is a large $\mathrm{T}$, large $\mathrm{N}$ data set, the PMG appears feasible. The mathematical background of the PMG model is described in the following:

\section{Adapted Model}

When adapting the general model to our case, we obtain the following long-run function:

$$
\begin{aligned}
R E P_{i t}= & \theta_{0 t}+\theta_{1 t \text { Chernobyl }_{t}}+\theta_{2 \text { tbarakit }_{t}} \\
& +\theta_{3 t \text { Fukushima }_{t}}+\theta_{4 t B X_{i t}}+\mu_{i}+\epsilon_{i t}
\end{aligned}
$$

where $i=1,2, \ldots, N$ is the number of countries, $t=1$, $2, \ldots, T$ the time span, and $Y_{i t}$ the respective dependent variable. $X_{i t}$ stands for the control and explanatory variables and $\mathrm{B}$ is the vector of corresponding coefficients. According to a cointegration test, the data appears to be cointegrated $\mathrm{I}(1)$ and the error term is an $\mathrm{I}(0)$ process for all $i$. This transforms the $\operatorname{ARDL}(1,1,1)$ dynamic panel specification of Eq. 9 into our basic regression equation:

$$
\begin{aligned}
\left.\Delta \operatorname{In}_{(R E P}\right)_{i t}= & \phi_{i} \theta_{0 i}+\theta_{1 i} \text { Chernobyl }_{i t} \\
& +\theta_{2 i} \text { Ibaraki }_{i t}+\theta_{3 i} \text { Fukushima }_{i t} \\
& +\theta_{4 i} \boldsymbol{B} \boldsymbol{X}_{i t} \\
& +\delta_{11 i} \Delta \text { Nuclear Accidents }_{i t} \\
& +\delta_{41 i} \Delta \operatorname{In}(\boldsymbol{B} \boldsymbol{X})_{i t}+\epsilon_{i t}
\end{aligned}
$$

where $\phi_{i}=-\left(1-\lambda_{1}\right), \theta_{0 i}=\frac{\mu_{i}}{1-\lambda_{1}}, \theta_{i t}=\frac{\delta_{i 0}+\delta_{i 1 i}}{1-\lambda_{1}}$, and $\phi_{i}=$ $-\left(1-\lambda_{i}\right)$. The error correction speed of adjustment parameter is $\phi_{i}$. The long-run coefficients are $\theta_{1 i}, \theta_{2 i}, \ldots$, $\theta_{N i}$

\section{Supplementary information}

Supplementary information accompanies this paper at https://doi.org/10. 1186/s13705-020-00256-3.

Additional file 1:. Appendix tables. Appendix table 1: Correlation matrix. Appendix table 2: List of OECD countries. Appendix table 3: Unit root tests for the dependent variable (REP (logs)). Appendix table 4: Unit root tests for the independent variables. Appendix table 5: Kao test for cointegration. Appendix table 6: Pedroni cointegration test.

\section{Acknowledgements}

We would like to thank Maija Ozola for proofreading and two unknown reviewers who helped improve a lot the quality of the paper.

\section{Authors' contributions}

SE: Theory, collected data, econometrics, and methodology. AT: Introduction and theory. TG: Theory, econometrics, discussion. The authors read and approved the final manuscript.
Funding

Not applicable

Availability of data and materials

Additional file 1

Ethics approval and consent to participate

Not applicable

Consent for publication

Not applicable

Competing interests

Not applicable

Author details

${ }^{1} \mathrm{TU}$ IImenau, Ehrenbergstr. 29, 98684 IImenau, Germany. ${ }^{2}$ London College of Communication, Elephant \& Castle London, London SE1 6SB, UK.

Received: 27 November 2018 Accepted: 4 May 2020

Published online: 26 May 2020

\section{References}

1. M Allen, P Antwi-Agyei, F Aragon-Durand, M Babiker, P Bertoldi, M Bind, S Brown, M Buckeridge, I Camilloni, A Cartwright, et al. 2019.

2. Weitzman ML (2015) A review of William Nordhaus' the climate casino: risk, uncertainty, and economics for a warming world. Rev Environ Econ Policy 9(1):145-146

3. Jon Barnett and W. Neil Adger. Climate dangers and atoll countries. Climatic Change, 61(3):321-337, Dec 2003. ISSN 1573-1480. doi: https://doi.org/10. 1023/B: CLIM.0000004559.08755.88

4. Anthony Costello, Mustafa Abbas, Adriana Allen, Sarah Ball, Sarah Bell, Richard Bellamy, Sharon Friel, Nora Groce, Anne Johnson, Maria Kett, et al. Managing the health effects of climate change: Lancet and University College London Institute for global health commission. The Lancet, 373(9676):1693- 1733, 2009.

5. IEA. CO2 Emissions from Fuel Combustion 2018. International Energy Agency, 2018

6. William $D$ Nordhaus. A review of the stern review on the economics of climate change. Journal of economic literature, 45(3):686-702, 2007.

7. Lawrence C Hamilton, Erin Bell, Joel Hartter, and Jonathan D Salerno. A change in the wind? US public views on renewable energy and climate compared. Energy, Sustainability and Society, 8(1):11, 2018.

8. Sandra T Marquart-Pyatt. Contextual influences on environmental concerns cross-nationally: a multilevel investigation. Social science research, 41(5): 1085-1099, 2012.

9. Sandra T Marquart-Pyatt. Are there similar sources of environmental concern? Comparing industrialized countries. Social Science Quarterly, 89(5): 1312-1335, 2008.

10. Sandra T Marquart-Pyatt. Concern for the environment among general publics: a cross-national study. Society \& Natural Resources, 20(10):883-898, 2007

11. Evan Herrnstadt and Erich Muehlegger. Weather, salience of climate change and congressional voting. Journal of Environmental Economics and Management, 68(3):435-448, 2014.

12. R Alexakhin, L Anspaugh, M Balonov, B Batandjieva, F Besnus, H Biesold, I Bogdevich, D Byron, Z Carr, G Deville-Cavelin, et al. Environmental consequences of the Chernobyl accident and their remediation: twenty years of experience. Report of the Chernobyl Forum Expert group "Environment". International Atomic Energy Agency, 2006.

13. Sergey $\vee$ Fesenko, Rudolf M Alexakhin, Mikhail I Balonov, lossif M Bogdevitch, Brenda J Howard, Valery A Kashparov, Natalia I Sanzharova, Alexey V Panov, Gabriele Voigt, and Yury M Zhuchenka. An extended critical review of twenty years of countermeasures used in agriculture after the Chernobyl accident. Science of the total environment, 383(1-3):1-24, 2007

14. S Yasumura, A Goto, S Yamazaki, and MR Reich. Excess mortality among relocated institutionalized elderly after the Fukushima nuclear disaster. public health, 127(2):186-188, 2013.

15. Johan Matthijs Havenaar. After Chernobyl. Psychological factors affecting health after a nuclear disaster. 1996. 
16. Antony Millner and Héne Ollivier. Beliefs, politics, and environmental policy Review of Environmental Economics and Policy, 10(2):226-244, 2016.

17. Judi Pajo. Danger explodes, space implodes: the evolution of the environmental discourse on nuclear waste, 1945-1969. Energy, Sustainability and Society, 5(1):36, 2015.

18. Ann Stouffer Bisconti. Changing public attitudes toward nuclear energy. Progress in Nuclear Energy, 102:103-113, 2018.

19. Thomas A (1998) Birkland. Focusing events, mobilization, and agenda setting. J Public Policy 18(01):53-74

20. Glaser A (2011) After Fukushima: preparing for a more uncertain future of nuclear power. Electr J 24(6):27-35

21. Taghizadeh-Hesary F, Yoshino N, Rasoulinezhad E (2017) Impact of the Fukushima nuclear disaster on the oil-consuming sectors of Japan. J Comparative Asian Dev 16(2):113-134

22. Gerhartz-Muro JL, Kritzer JP, Gerhartz-Abraham A, Miller V, Pina-Amargós F, Whittle D (2018) An evaluation of the framework for national marine environmental policies in Cuba. Bull Mar Sci 94(2):443-459

23. Yang L, Ouyang H, Fang K, Ye L, Zhang J (2015) Evaluation of regional environmental efficiencies in China based on super-efficiency-DEA. Ecol Indic 51:13-19

24. Hoppe T, van den Berg MM, Coenen FHJM (2014) Reflections on the uptake of climate change policies by local governments: facing the challenges of mitigation and adaptation. Energy Sustainabil Society 4(1):8

25. Ross Beveridge and Kristine Kern. The Energiewende in Germany: background, developments and future challenges. Renewable Energy L. \& Pol'y Rev., 4:3, 2013.

26. Nesta L, Vona F, Nicolli F (2014) Environmental policies, competition and innovation in renewable energy. J Environ Econ Manag 67(3):396-411

27. Johnstone N, Hascic I, Popp D (2010) Renewable energy policies and technological innovation: evidence based on patent counts. Environ Resour Econ 45:133-155

28. Popp D (2002) Induced innovation and energy prices. Am Econ Rev 92(1): $160-180$

29. Jaffe AB, Newell RG, Stavins RN (2003) Technological change and the environment. Handbook Environ Econ 1:461-516

30. Fischer C, Newell RG (2008) Environmental and technology policies for climate mitigation. J Environ Econ Manag 55(2):142-162

31. Kozluk T, Zipperer V (2015) Environmental policies and productivity growth. OECD J Econ Stud 2014(1):155-185

32. Peter D Lund. Effects of energy policies on industry expansion in renewable energy. Renew Energy, 34(1):53-64, 2009.

33. Nohrstedt D (2005) External shocks and policy change: three Mile Island and Swedish nuclear energy policy. J Eur Public Policy 12(6):1041-1059

34. Jenkins-Smith HC, Sabatier PA (1994) Evaluating the advocacy coalition framework. J Public Policy 14(02):175-203

35. Schlager E (1995) Policy making and collective action: defining coalitions within the advocacy coalition framework. Policy Sci 28(3):243-270

36. Sotirov M, Memmler M (2012) The advocacy coalition framework in natural resource policy studies - recent experiences and further prospects. Forest Policy Econ 16:51-64

37. Sabatier PA (1998) The advocacy coalition framework: revisions and relevance for Europe. J Eur Public Policy 5(1):98-130

38. Sabatier PA (1987) Knowledge, policy-oriented learning, and policy change: an advocacy coalition framework. Knowledge 8(4):649-692

39. Henry AD, Ingold K, Nohrstedt D, Weible CM (2014) Policy change in comparative contexts: applying the advocacy coalition framework outside of Western Europe and North America. J Comparative Policy Analysis Res Practice 16(4):299-312

40. Kübler D (2001) Understanding policy change with the advocacy coalition framework: an application to Swiss drug policy. J Eur Public Policy 8(4):623-641

41. John P (2003) Is there life after policy streams, advocacy coalitions, and punctuations: using evolutionary theory to explain policy change? Policy Stud J 31(4):481-498

42. Johnstone N, Haščič I, Kalamova M (2010), "Environmental Policy Design Characteristics and Technological Innovation: Evidence from Patent Data", OECD Environment Working Papers, No. 16, OECD Publishing, Paris. https:// doi.org $/ 10.1787 / 5 \mathrm{kmjstwtqwhd-en.}$

43. McConnell A (2008) Ripples not waves: a policy configuration approach to reform in the wake of the 1998 Sydney water crisis. Governance 21(4):551-580
44. Arjen Boin and Paul T Hart. The crisis approach. In Handbook of Disaste Research. Springer, January 2007. ISBN 978-0-387-73952-6. doi: 10.1007/9780-387-32353-4_3. URL http://dx.doi.org/https://doi.org/10.1007/ 978-0-38732353-4_3.

45. John TS Keeler (1993) Opening the window for reform mandates, crises, and extraordinary policy-making. Compar Pol Stud 25(4):433-486

46. Scott C Flanagan. Models and methods of analysis. Crisis, choice, and change: historical studies of political development. Boston: Little, Brown, 1973.

47. Uriel Rosenthal, Arjen Boin, and Louise K Comfort. Managing crises: Threats, dilemmas, opportunities. Charles C Thomas Publisher, 2001.

48. Hewitt K (1983) aThe idea of calamity in a technocratic age «. Interpretations of Calamity: From the Viewpoint of Human Ecology. Allen and Unwin, London

49. Birkland TA (1997). After disaster: Agenda setting, public policy, and focusing events. Georgetown University Press

50. Thomas Birkland and Megan Warnement. Defining, explaining, and testing the role of focusing events in agenda change: 30 years of focusing event theory. In APSA 2013 Annual Meeting Paper, 2013.

51. Nohrstedt D, Weible CM (2010) The logic of policy change after crisis: proximity and subsystem interaction. Risk, Hazards \& Crisis in Public Policy 1(2):1-32

52. Sabatier PA, Jenkins-Smith HC (1999) The advocacy coalition framework: an assessment. Theories Policy Process 118:188

53. Sabatier P. (2019). Theories of the policy process. Routledge

54. March JG, Olsen JP (1996) Institutional perspectives on political institutions. Governance 9(3):247-264

55. Dopfer K, Potts J (2008) The general theory of economic evolution. Routledge, London and New York

56. Dopfer K (2004) The economic agent as rule maker and rule user: homo sapiens oeconomicus. J Evol Econ 14(2):177-195 ISSN 09369937

57. Kurt Dopfer, John Foster, and Jason Potts. Micro-meso-macro. Journal of Evolutionary Economics, V14(3):263-279, July 2004. URL http://dx.doi. org/ https://doi.org/10.1007/s00191-004-0193-0.

58. Pierson P (2000) Increasing returns, path dependence, and the study of politics American political science review, 94(02):251-267

59. IAEA. The international nuclear and radiological event scale (ines), 2016

60. Baumgartner FR, Jones BD (1991) Agenda dynamics and policy subsystems. J Polit 53(04):1044-1074

61. Nohrstedt D (2008) The politics of crisis policymaking: Chernobyl and Swedish nuclear energy policy. Policy Stud J 36(2):257-278

62. Kingdon JW (2003) Agendas, alternatives, and public policies. 2003

63. Zahariadis N (2014) Ambiguity and multiple streams. Theories Policy Process:25-58

64. Scartascini C, Cruz C, Keefer P (2018) The database of political institutions 2017 (dpi2017)

65. Dasgupta S, Mody A, Roy S, Wheeler D (2001) Environmental regulation and development: a cross-country empirical analysis. Oxf Dev Stud 29(2):173-187

66. International Atomic Energy Agency (2008) Ines: the international nuclear and radiological event scale user's manual

67. Neumayer $E$ (2004) The environment, left-wing political orientation and ecological economics. Ecol Econ 51(3-4):167-175

68. Dietz T (1998) Paul C stern, and Gregory a Guagnano. Social structural and social psychological bases of environmental concern. Environ Behav 30(4): 450-471

69. Dunlap RE, Xiao C, McCright AM (2001) Politics and environment in America: partisan and ideological cleavages in public support for environmentalism. Environ Politics 10(4):23-48

70. Taghizadeh-Hesary F, Yoshino N (2019) The way to induce private participation in green finance and investment. Financ Res Lett 31:98-103

71. Yoshino N, Taghizadeh-Hesary F, Nakahigashi M (2019) Modelling the social funding and spill-over tax for addressing the green energy financing gap. Econ Model 77:34-41

72. Hausman J, Hall BH, Griliches Z (1984) Econometric models for count data with an application to the patents-r\&d relationship. Econometrica 52(4):909938 ISSN 00129682:14680262

73. Blundell R, Griffith R, Windmeijer F (2002) Individual effects and dynamics in count data models. J Econ 108(1):113-131

74. Trainer FE (1995) Can renewable energy sources sustain affluent society? Energy Policy 23(12):1009-1026 
75. James M Broughton, Pui Kuan, David A. Petti, and E. L. Tolman. A scenario of the three Mile Island unit 2 accident. Nuclear Technology, 87(1):34-53, 1989. Doi: 10.13182/NT89-A27637. URL. https://doi.org/https://doi.org/10. 13182/NT89-A27637.

76. Renn O (1990) Public responses to the Chernobyl accident. J Environ Psychol 10(2):151-167

77. Rosa EA, Dunlap RE (1994) The polls - poll trends: nuclear power: three decades of public opinion. Public Opin Q 58(2):295-324

78. Flavin C (1987) Chernobyl: the political fallout in Western Europe. In Forum for Applied Research and Public Policy (Summer):16-28

79. Hogan J, Feeney S (2012) Crisis and policy change: the role of the political entrepreneur. Risk Hazards Crisis Public Policy 3(2):1-24

80. Sabatier P, Weible C (2007) The advocacy coalition: innovations and clarifications. Theories Policy Process 2:189-220

81. Franz Urban Pappi and Christian H. C. A. Henning. Policy networks: more than a metaphor? Journal of Theoretical Politics, 10(4):553- 575, October 1998. URL https://ideas.repec.org/a/sae/jothpo/v10y1998i4p553-575.html.

82. Schneider V (1992) The structure of policy networks. Eur J Polit Res 21(1-2): 109-129

83. Leifeld P (2013) Reconceptualizing major policy change in the advocacy coalition framework: a discourse network analysis of German pension politics. Policy Stud J 41(1):169-198

84. Ingold K (2011) Network structures within policy processes: coalitions, power, and brokerage in Swiss climate policy. Policy Stud J 39(3):435-459

\section{Publisher's Note}

Springer Nature remains neutral with regard to jurisdictional claims in published maps and institutional affiliations.

Ready to submit your research? Choose BMC and benefit from:

- fast, convenient online submission

- thorough peer review by experienced researchers in your field

- rapid publication on acceptance

- support for research data, including large and complex data types

- gold Open Access which fosters wider collaboration and increased citations

- maximum visibility for your research: over $100 \mathrm{M}$ website views per year

At BMC, research is always in progress.

Learn more biomedcentral.com/submissions 